\title{
Cultural and Mental Peculiarities of Innovation Processes' Development in Ukraine in the Context of Industry 4.0
}

\author{
Andrii Karpenko ${ }^{1 *}$, Tetiana Naumchuk $^{1}$ and Natalia Karpenko ${ }^{1}$ \\ 1"Zaporizhzhia Polytechnic" National University, 69063, Zaporizhzhia, Ukraine
}

\begin{abstract}
The article deals with cultural and mental peculiarities of innovation processes' development in Ukraine in the context of Industry 4.0. There has been presented a comparative rating of some world countries according to NRI, ICT, GOI, IDI, GII indices and the position of Ukraine over the past decade has been stated. The main results of innovation activity in Ukraine that lie in low innovative activity have been characterized. The factors that hinder innovation activity are insufficient level of educational training, low activity in offering innovative ideas, no incentive to create something new etc. In addition, a significant negative impact on innovation activity is exerted by cultural and mental factors of the population, a considerable part of which does not have entrepreneurial skills. There have been substantiated some socio-cultural and mental characteristics of Ukrainians that determine their innovative activity, namely reduce the competitiveness of the country's human capital both at the personal and national levels. The solution of the problem has been proposed which implies cooperation between three main components of the innovative economy - "science - education - production" as a common system.
\end{abstract}

\section{Introduction}

Changes in the modern world are taking place at a very rapid pace, are mostly radical in nature and are accompanied by the emergence of self-driving cars, 3D printers, nanotechnologies, etc. Leading positions in the modern economy are occupied by industries that are based on the use of information technologies. For a long time, the scientific community has been talking about the onset of the Fourth Industrial Revolution, which will change the labor market, economy and education in general: "the Fourth Industrial Revolution can "robot humanity" and for many people it will irreparably change the way their work, environment, family life and identity itself look" [1].

The concept of Industry 4.0 provides increasing automation of absolutely all processes and stages of production: from product design to delivery to the end user, taking into account the requirements of the latter. Industry 4.0 also implies a well-established production without human intervention, ensuring maximum efficiency [2], which is rather contravercial though.

Industry 4.0 is an established global innovation program aimed at making manufacturing facilities more intelligent, efficient and flexible [3]. Technologies 4.0 are among the priority factors of competitiveness and the leaders of industrial enterprises have a justified need for more investment in the development of new technologies, as all / most of industrial enterprises depend on digital transformation [2].

We cannot but agree that "given the complexity and scope of industrial digitalisation, much of the academic research focuses on technological and organisational problems. Addressing "human factors" and in particular conceptualising and measuring human readiness for digitalised work receives less attention, and remains an early-stage project. Nevertheless, this project is crucial to the success of Industry 4.0 because aside from a few 'dark factory' scenarios, humans are considered more adaptive than machine entities and vital to future production". The technology has made possible new products and services that have generated significant transformations in both personal and professional life, emphasizing the interaction between machines and people [4]. Accordingly, a person should change and at the same time perceive the environment, resources and attitude to education and production in a new way.

It should be noted that the Industrial 4.0 Revolution inevitably causes some disadvantages. The reduction of creativity may occur due to the automation of machines and the disappearance of human capital from the production technology. Human capital can generate controversy with its creativity, while devices are optimized, set up, and programmed to perform, despite the errors that may occur [5].

To be competent in the modern world, to adjust to the changing environment, people have to acquire new skills which contribute to the human capital. Among them the researchers identify technical knowledge and abilities, which imply computer programming / coding abilities, data and information processing and analytics, specialized knowledge of manufacturing activities and processes, organizational and process understanding, interdisciplinary / generic knowledge about technologies, statistical knowledge; managerial competencies, which involve creativity, entrepreneurial thinking, problem / conflict solving, decision making, research and analytical skills, efficiency orientation; 
social competencies, which include intercultural and language skills, communication skills, leadership skills, ability to be compromising and cooperative, to work in a team, to transfer knowledge and accept change [6].

Besides, the notion of entrepreneurial activity intermingles with the national culture, which is the set of shared values, beliefs, and expected behaviors. Researchers distinguish three broad research streams that address national culture and entrepreneurship. The first research stream focuses on the impact of national culture on the aggregate measures of entrepreneurship such as national innovative output or new businesses created. The second stream addresses the association between national culture and the characteristics of individual entrepreneurs. Within this stream of literature, researchers have examined the values, beliefs, motivations, and cognitions of entrepreneurs across cultures. The third stream explores the impact of national culture on corporate entrepreneurship [7].

In the study the dialectical and empirical methods were applied to consider the evolution of cultural and mental traits of the population, the consequences and possible reserves of innovation activity's growth. Methods of comparative analysis and dynamics series were used to compare actual data of the reporting and previous years, identify changes in indicators and parameters of innovative enterprises' functioning. Materials from international organizations for evaluating indices and ratings of Ukraine and individual European countries, as well as the state statistics service of Ukraine, were used for the analysis.

\section{Main results of the research}

\subsection{The level of innovativeness of Ukraine among European countries}

An important indicator of a country's potential and development opportunities in the information society is the network readiness index (NRI), which characterizes close relationship between ICT development and economic well-being. ICTs today permeate all areas of activity and improve their quality and effectiveness. The leading role of ICTs in developing innovation, increasing productivity and competitiveness, diversifying the economy and stimulating business activity is increasingly recognized today, which contributes to development and is possible with the effective use of intellectual assets of human potential.

According to the Global Information Technology Report published by the World Economic Forum, Ukraine ranked 71st among 143 countries in 2015 in terms of ICT development based on the Network Readiness Index (NRI) (fig. 1). Singapore and Sweden were the leaders of the rating on the network readiness index in 2015-2016, while Ukraine was located between Trinidad and Tobago and Kuwait.

In 2020 Ukraine took the best position in the rating, which proves positive changes in the national economy. In addition, since 2019, the NRI has been revised to reflect how technology and people need to be integrated into effective governance structure in order to make the right impact on our economy, society, and environment. NRI has become focused on digital transformation and is calculated based on 60 variables.

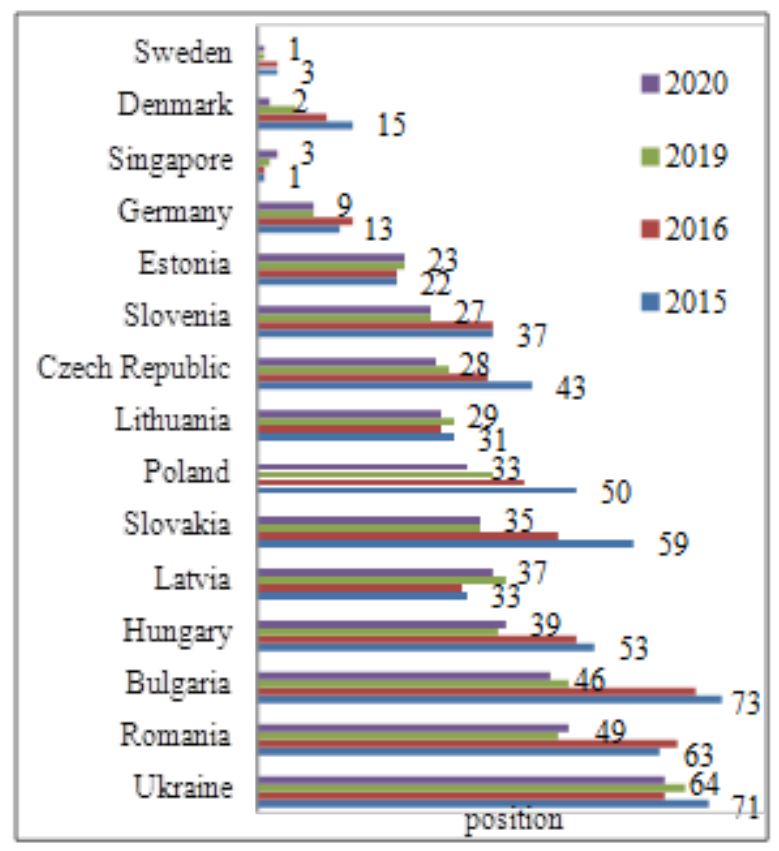

Fig. 1. Ukraine's position among different world countries in terms of Network Readiness Index in 2015-2020. Source: built on the basis of $[8,9,10]$

The presented comparative rating of some world countries proves significant reserves in Ukraine for improvement, since European countries have significantly better conditions for the use of ICT and, accordingly, the use of intellectual assets of human potential [11].

The reason for Ukraine's low position in the rating is still the lag in terms of components that characterize the political and regulatory environment and the low level of ICT use by the government, and the advantage is the availability of ICT. The components of the network readiness index of Ukraine represent a clear upward trend, but the growth rate in the world for the development of network readiness is slightly higher than in Ukraine, which confirms a low level of current changes that do not contribute to the highest level of use of intellectual assets of human potential.

The ICT Development Index (IDI) of Ukraine for 2010-2017 increased by 1.21 , but the country's position in the corresponding rating worsened from 69 to 79 (176 countries of the world in 2017 and 167 countries of the world in 2010) (fig. 2). That is, despite positive changes in the resource supply and level of ICT use, as well as the development of ICT skills, their growth rates are lower than required by modern world changes. This is what proves the insufficient level of use of intellectual assets of human potential in comparison with the developed countries.

Ukraine shows positive dynamics in certain indicators of the ICT Development Index (ICT Development Index - IDI), based on the assessment of 
access to ICT, the use of ICT, as well as ICT skills, i.e. practical knowledge of these technologies among the population. An increase in the share of families who have a computer; an increase in the share of residential premises connected to the Internet, the share of the population who use the Internet are the factors, which give grounds to assume more intensive use of ICT, including in the educational sphere. According to the ICT Development Index for 2015-2017, the first places were occupied by South Korea, Denmark, Sweden.

In 2010-2020, Ukraine's position in the Global Opportunity Index (GOI) rating, which takes into account a set of factors that contribute to attracting foreign direct investment (main economic indicators; ease of doing business; quality of regulation; rule of law), worsened by 5 positions.

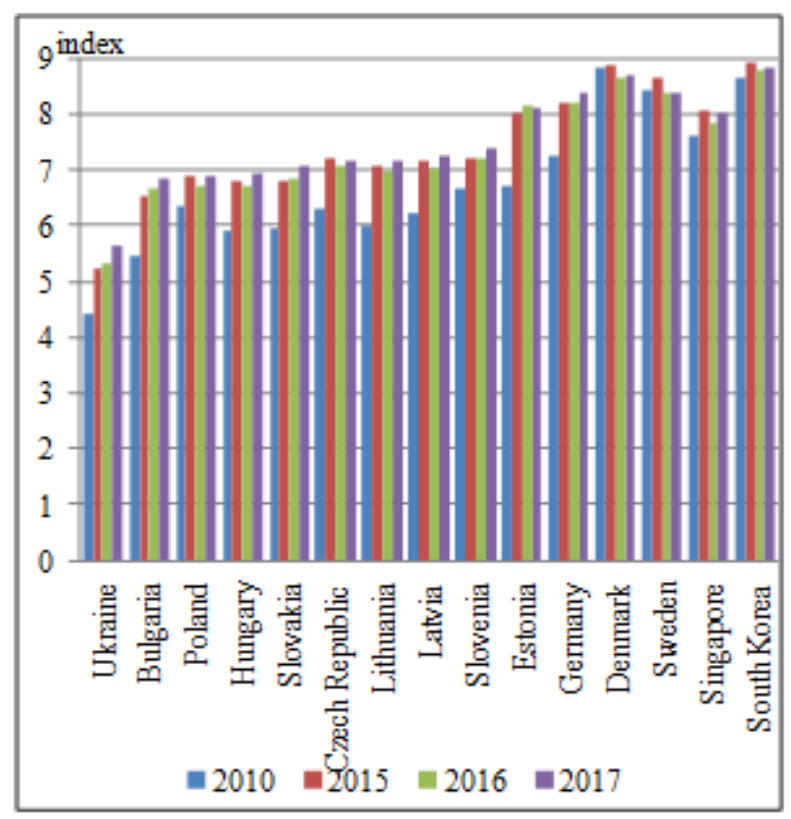

Fig. 2. Dynamics of the ICT development index (IDI) in Ukraine, selected CIS countries and Eastern Europe. Source: based on data from the International Telecommunication Union [12]

However, according to the ICT Development Index in Ukraine for 2008-2017, the position worsened by 20 positions (fig. 3).

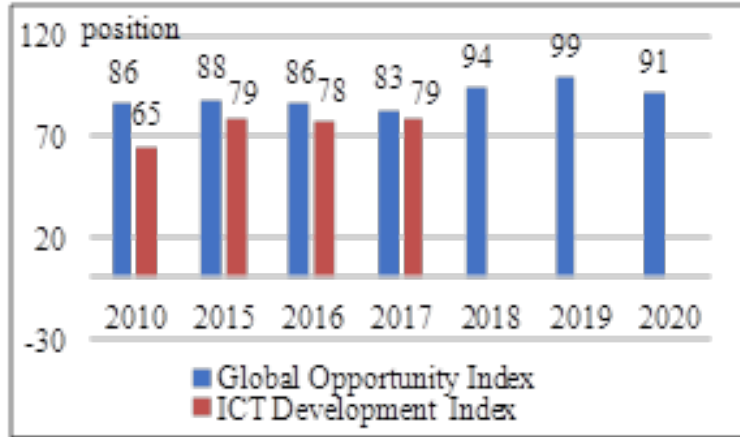

Fig. 3. Global Opportunity Index (GOI): changing Ukraine's position in the rating.

Source: based on data from the International Telecommunication Union [12]
According to the Global Innovation Index (GII) in 2020, covering 131 economies of the world, Ukraine took one of the highest positions in the last 10 years 45th place (fig. 4).

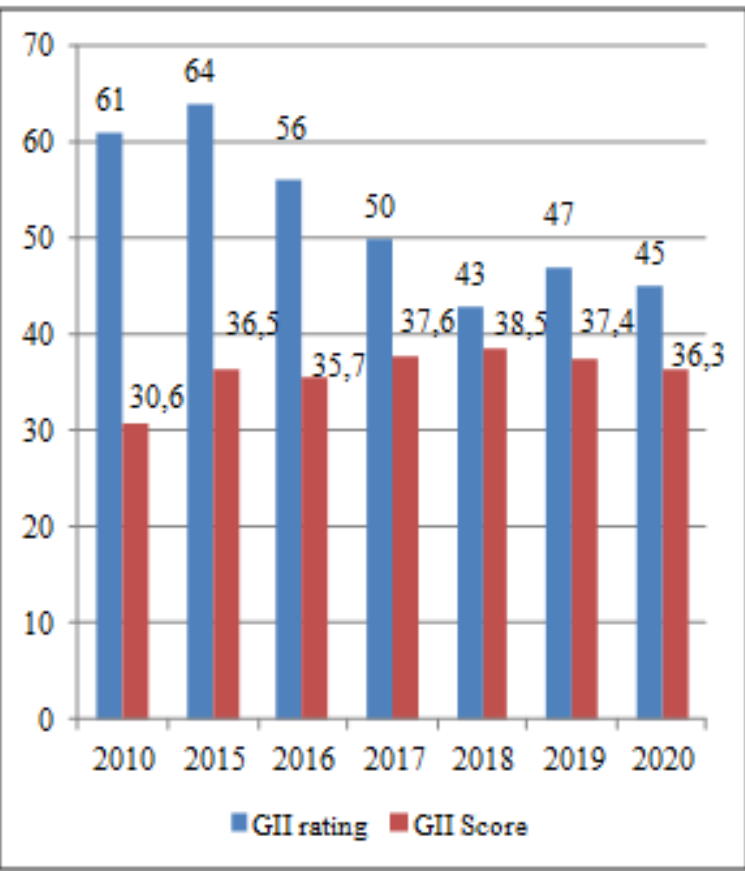

Fig. 4. Dynamics of the Global Innovation Index (GII) and rating of Ukraine.

Source: built on the basis of data [13]

The study of the problem shows that in recent years the improvement of positions is due to a high coefficient of innovation efficiency, that is, the ratio of the result obtained to innovative resources. Ukraine has demonstrated the highest indicators of innovation in education, science and business, but institutions and infrastructure remain the least innovative.

In 2018, Ukraine ranked first in the below average income group, and in 2017 - the second one after Vietnam. Switzerland, Sweden, the Netherlands, the United States, Great Britain, Denmark, Singapore, Finland, Germany and Ireland remain the leaders for several years in a row, while Ukraine lags behind the countries of Eastern Europe (fig. 5).

Human capital is the basis of Ukrainian innovation competitiveness, which in 2010-2020, although it decreased in the rating from 36 to 39 positions, but consistently remains decisive in the formation of the GII. Its indicator reduced due to the decrease in public spending on education and science. The fundamental factor hindering innovative development is the low level of R\&D costs, which leads to the search for other sources of funding and the migration of scientists outside of Ukraine. Insufficient development of infrastructure and innovation chains, unfavorable political situation and environmental sustainability also have a negative impact. A significant role also belongs to creativity, which in 2020 was on the 44th position (intangible assets, creative goods and services, online creativity) (fig. 6). 


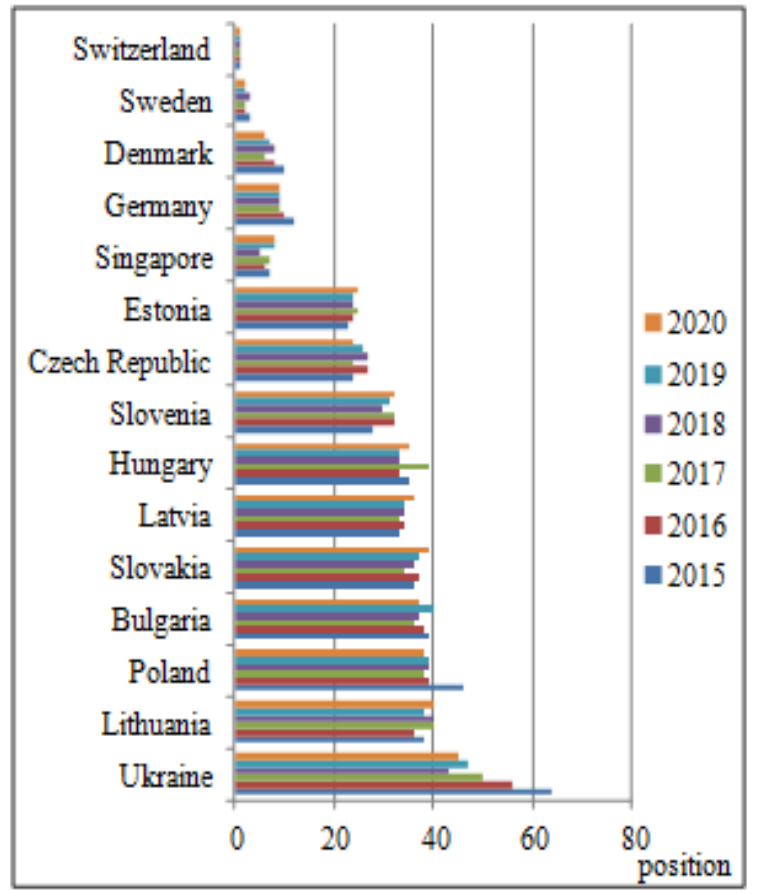

Fig. 5. Rating of the Global Innovation Index (GII) of Ukraine and some world countries.

Source: built on the basis of data [13]

The greatest positive changes for the entire period were achieved in terms of the effectiveness of scientific research (moving Ukraine from 75 to 25 positions in the rating, including in terms of creation, influence and dissemination of knowledge). According to the business experience sub-index, Ukraine has risen by 20 positions and ranked 54th in 2020 (in terms of the number of knowledge workers, innovative connections, and knowledge perception).

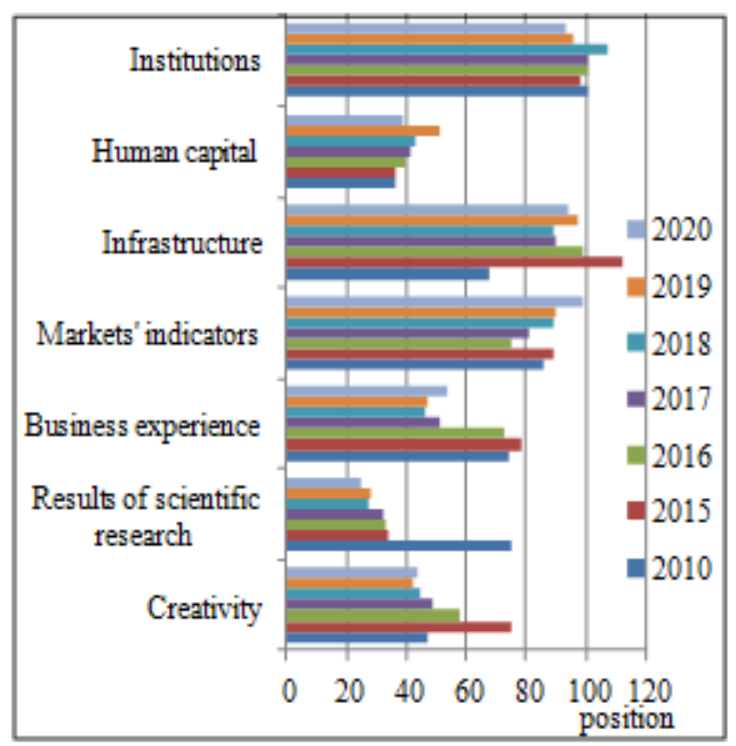

Fig. 6. Dynamics of sub-indices of the Global Innovation Index (GII) for Ukraine for 2010-2020.

Source: built on the basis of data [13]

Infrastructure development and market indicators (in terms of loans, trade and competition, investment), as well as the "institutions" sub-index (political environment, regulatory environment, business environment) still have the worst results of the reform in Ukraine.

\subsection{Main results of innovation activity in Ukraine}

In 2000-2019, the number of enterprises implementing innovations decreased by 530 units, or more than 2 times. The share of industrial enterprises that introduced innovations increased by $2.3 \%$. Fluctuations in these indicators are partly due to changes in the research methodology, although they have never approached the threshold value $(25 \%)$ and are much lower than the same indicator in developed countries (70-80\%) (fig. 7).

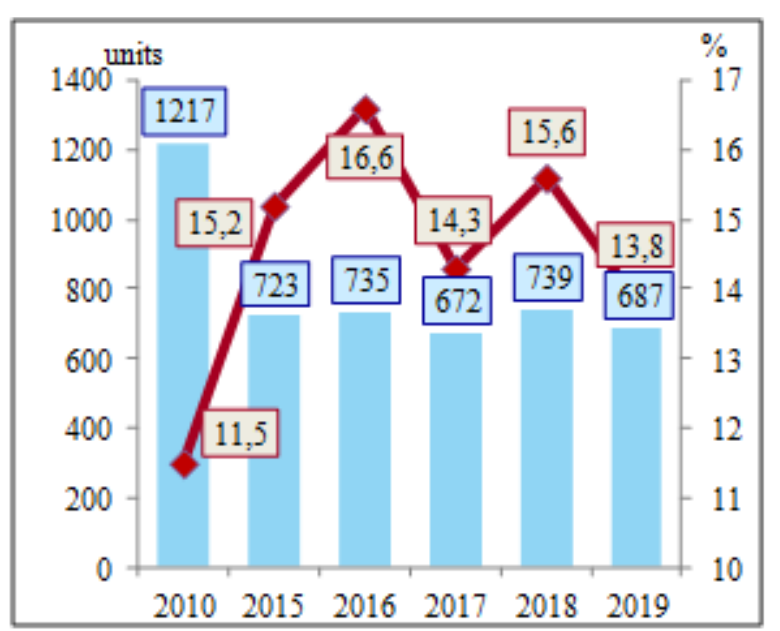

Fig. 7. Number of enterprises that implemented innovations (units) and its share in the total number of industrial enterprises (\%).

Source: built on the basis of data [14]

In 2010-2019, the number of enterprises selling innovative products in Ukraine decreased by 522 (from 964 to 442), the share of which in the total volume of industrial products is very low (decreased from 3.8 to $1.3 \%)$.

A significant obstacle to increasing the volume of commercialization of innovations in Ukraine is the low innovative activity of entrepreneurship (fig. 8).

In 2005-2017, the share of enterprises that were engaged in innovative activities and introduced innovations increased by 2 and 2.3 percentage points, respectively, while the share of enterprises that sold innovative products new to the market decreased by 2.2 percentage points. That is, in the domestic industry, mainly innovative products are introduced, which are new only for the enterprise.

Consequently, the indicators of innovation activity in Ukraine are low compared to current global trends, and low level of potential demand for innovative products and return on investment explains small volume of innovation implementation. 


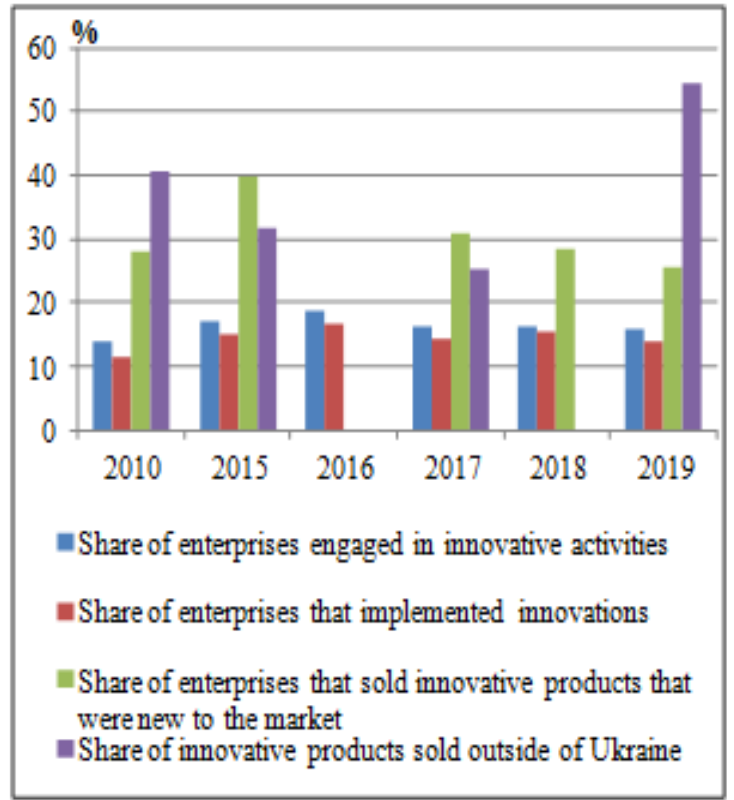

Fig. 8. Dynamics of innovative activity of industrial enterprises in Ukraine, \%.

Source: built on the basis of data [14]

In 2010-2019, there is an ambiguous trend in Ukraine, when peak volumes occurred in 2008. indicators of innovation activity in Ukraine are low compared to modern global trends, respectively, therefore, the indicators of innovation implementation in Ukraine are too low (fig. 9).

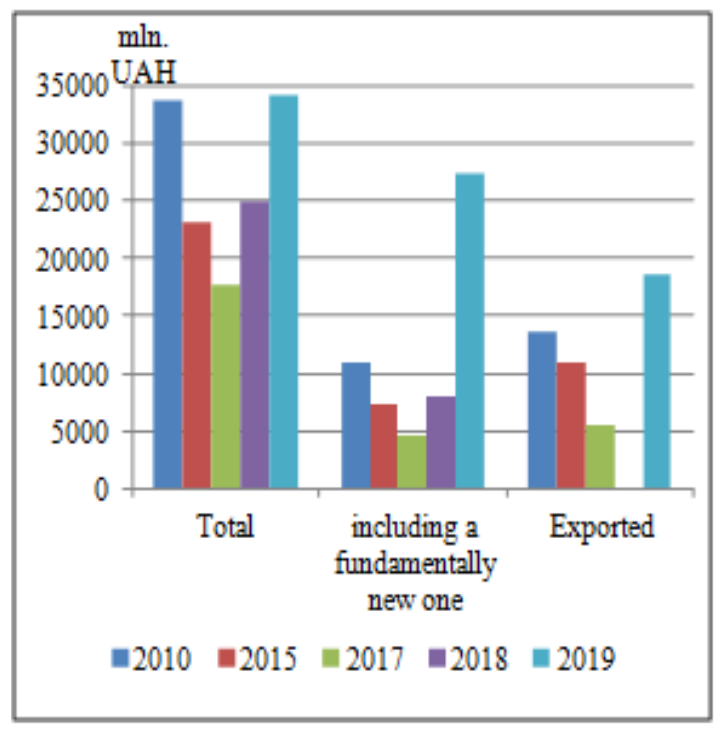

Fig. 9. Volume of innovative products sold in Ukraine, mln. UAH.

Source: built on the basis of data [14]

In recent years, the share of enterprises that implemented innovations in Ukraine has decreased. Among the areas of innovation implementation, the development of innovative types of products prevails, the number of which decreased by 260 units in 20102019. The volume of new technological processes implemented increased by 275 and generally did not have any drastic changes.
After some recovery in 2015, the number of technologies implemented, including low-waste and resource-saving ones, fell below the level of 2010. Perhaps, not the least role here was played by the fact that enterprises began to purchase fewer new technological processes (fig. 10).

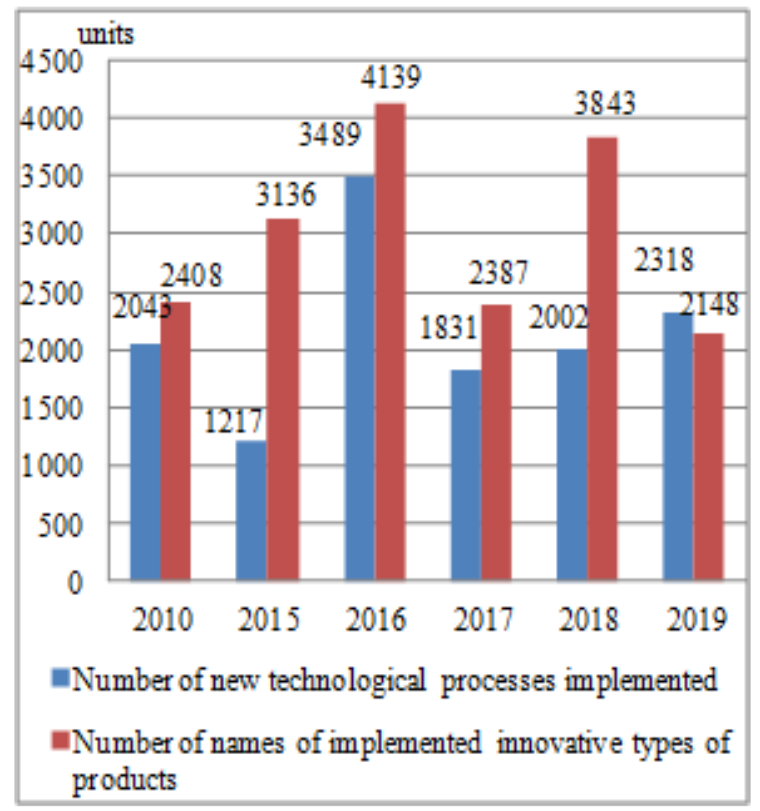

Fig. 10. Volume of innovation implementation at industrial enterprises of Ukraine, units.

Source: based on data from the State Statistics Service of Ukraine [14]

It is worth noting that many enterprises do not use innovative developments due to a number of factors that hinder innovation activity: insufficient level of educational training; low activity in offering innovative ideas; there is no incentive to create something new.

These indicators of innovation activity of industrial enterprises in Ukraine indicate the lack of NIS development, a stable development strategy of the country, which causes instability and situativeness of the development of innovative factors of economic growth. In general, the indicators of innovative and technological development of the real sector of the economy have remained almost stable in recent years. This highlights the existing pattern regarding the importance of the stabilizing role of innovation factors in economic development.

\subsection{Cultural and mental characteristics of Ukrainians}

In the modern conditions of world economy globalization, sharp increase in competition, spread and development of innovations, attitude to the main productive force of society - man, to his value and motivational activities is changing. Nowadays competitiveness and development are mainly determined by the availability of innovative proposals and their rapid implementation. The only factor of production that has a creative component and acts as a generator of innovative ideas and their performer is a 
person (human resources). In this regard, there is a need to form and implement motivating measures at the macro, meso and micro levels of economic activity to activate the innovative activity of human resources. The issue of creating a favorable environment that would encourage the population to innovate and perceive innovative changes becomes urgent.

On the one hand, Florida (2002) in his work "The Rise of the Creative Class" [15] puts a great emphasis on creativity laying in the conducted activities or processes beyond currently accepted standard and being the decisive source of competitive advantage. The so-called "creative class" members have certain lifestyles distinct from other classes, such as: individuality, diversity, authenticity, identity, casual instead of intimate social interaction, and self-defining.

The three key factors that influence regional growth are 3T's (tolerance, which is the openness to creative people worldwide; talent is represented by the relative concentration of the creative class and Talent Index (the percentage of bachelor holders); and technology the proxies for which are Innovation Index (patents granted per capita) and High-tech Index) [16].

On the other hand, motivations for becoming an entrepreneur have generally been categorized as either push/pull situational factors or personal characteristics. A number of studies have come to the conclusion that new venture initiation often occurs as a result of situational pushes or pulls that include frustration with present life-style, childhood, family environment, education, age, work history, role models, and support networks. Some individuals are pushed into entrepreneurship by negative factors such as dissatisfaction with existing employment, loss of employment, and career setbacks [17].

Innovation activity in Ukraine is officially one of the priorities, however, its support and incentives by the state are often only declared. Due attention is not paid to the formation and increase of innovation activity. In addition, a significant negative impact on innovation activity is exerted by cultural and mental factors of the population, a significant part of which does not have entrepreneurial skills and or is not able to use them.

In such conditions, increasing the innovation activity of the population and business entities is one of the most pressing issues for the development of the Ukrainian economy, since innovations create the basis for the competitiveness of the country and individual business entities. Significant priorities of innovative activity of enterprises are innovative labor and intellectual assets of human potential, determined by the innovative activity of the individual.

Economic behavior of a person and his innovative activity is determined by many factors, among which the leading role is played by public consciousness, which is formed under the influence of generally accepted values, traditions, socio-cultural and ethnic characteristics. Among the various components of behavioral influence on the life of a person and an individual nation, an important role, in our opinion, is played by mentality.
We could associate mentality with corporate culture. These two notions correlate at macro and micro levels and imply the following aspects:

- behavioural aspects in the communication of people: language, customs, and traditions, rituals;

- collective norms: unspoken standards and values adopted in the organization/society;

- official rules: publicly stated principles, which the organization/society tries to follow;

- formal philosophy: a variety of ideological and political principles governing the activities of the organization/society;

- unspoken rules of the organization/society;

- climate: the feeling transmitted to the organization through the external environment and the forms of interaction between employees;

- established skills: demonstration of certain skills in the performance of the task;

- the way of thinking: the way of thinking shared by employees of the company/members of the society, which determines the perception, thoughts, and language of the organization/people;

- a common understanding: arises when members of an organization/society communicate with each other;

- metaphors and integrated symbols: ideas, feelings, and images, through which the organization/society itself characterizes [18].

We consider it reasonable to use the term of "economic mentality", as the concept reveals the activity of a person (collective or community) in order to receive a certain reward. Since the country's economy is based on economic activity (any socially useful activity, the results of which are sold as a commodity), the use of the concept of "economic mentality" will be important in this direction.

We can say that the economic mentality is a certain consciousness of a person or the population as a whole, which develops historically, manifests itself in the unity of conscious and unconscious values, norms and attitudes reflected in the labor behavior of the population and expresses a system of value orientations and self - determination of the individual in the social, legal, political, historical and professional space.

In the post-Soviet space in general, and in Ukraine in particular, the mentality is one of the main problem that greatly affects the current economic situation. That is, significant transformations in the society and high rates of world knowledge are constantly integrated into the modern mentality and become one of the dominant factors of a developed economy [11]. Since the transformation of mentality is a long-term process, that is why the Ukrainian society is characterized by a certain conservatism of individual and social consciousness with its positive and negative characteristics, which to a certain extent hinders the socio-economic development of the country.

Let's consider through the prism of mentality the conditions for the development of intellectual assets of the human potential of Ukraine, namely, the education of society and the availability of highly qualified personnel. 
According to the World Bank ratings, Ukraine has continued to occupy the first positions in terms of general education of citizens in recent years.

The high level of the education index (average and expected duration of study) has a positive impact on the image of the country, since the current development of the economy depends on the ability to use new knowledge and innovations. The high education index of Ukraine indicates a high education of the population, however, the lag in coverage and quality of education is noticeable.

Ukraine has received such a high level of education of the population precisely because of its mental characteristics, since traditionally it has always been appropriate for the population to think about the determining role of education (especially higher education) in ensuring a successful career, even if this was not always confirmed by real knowledge and professional skills. Such priorities were significantly influenced by the system of power formation during the planned economy. Accordingly, the significant popularity of higher education, which was formed at the mental level of the population in the absence of effective state monitoring of the quality of education, regulation and planning in the educational sphere, caused the discrepancy between the quantitative and qualitative characteristics of the domestic education system and the needs of the economy. The current problem of Ukrainian society is precisely that a high level of education in domestic practice is not always identical to professionalism and cannot be the key to improving the economic situation.

As a result, the problems of disparity between supply and demand in the labor market and the discrepancy between the education system and the needs of the labor market in terms of qualification level and professional structure are constantly becoming more acute in Ukraine. This leads to a shortage of employees of certain professional groups, in particular workers. The structure of modern domestic education is characterized by a shift in vocational education in favor of higher education, which has led to an asymmetry of the labor market. The actual lack of a link between the level of education received and the level of income has led to a formal attitude to receiving education and a significant decrease in its quality. Accordingly, the level of intellectual assets of human potential remains insufficiently variable or slowly increases. Consequently, significant opportunities for further innovative development are lost, which can lead to irreversible destructive phenomena in the domestic economy.

Innovation activity in Ukraine remains very low. Peculiar are a number of negatives: paternalism of the majority of the Ukrainian population; social and political conformism; disregard for health and health care system; presence of "equalization" in wages and its low level, as a result - low quality of work and general negligence; lack of a clear national idea [19]. These traits significantly reduce the competitiveness of the country's human capital both at the personal and national levels, and do not contribute to the development of intellectual assets of human potential.

An important component of the new type of national mentality in the digital economy, in our opinion, is the susceptibility to change, awareness of the importance and necessity of innovative development for further progress. Scientists and practitioners are optimistic that there are still many people among the domestic population who are capable of innovative behavior and innovative activities. Taking this into account, an important task is to prioritize the development and implementation of comprehensive measures to improve the level and quality of higher education and stimulate innovative activity of the population and the corresponding development of intellectual assets of human potential. This, in our opinion, will contribute to the development of an innovative society, increase the volume of production and commercialization of innovations.

\subsection{Development of higher education and its impact on the Ukrainian economy}

Education, which is a process of mastering knowledge and skills in the context of socialization of the individual, aimed at reproducing the intelligence of the nation, determines its key place among other economic sectors. The level of education is a reflection of economic progress and ensures the country's competitiveness in the global market. Therefore, in the context of the digital economy in Ukraine, one of the determining conditions for development is education. In interaction with the labor market it can create prerequisites for the formation of human capital and commercialization of innovations as the basis for effective socio-economic innovation development of the country, since knowledge and qualifications are important factors for ensuring and implementing the socio-economic progress of society.

Education is not only a connecting, but also a constructive link in the system of three main components of the innovative economy - "science education - production". The educational potential acts simultaneously as a source of replenishment of science with personnel and as the main factor in mastering them, modern knowledge necessary to ensure the economic, social and cultural development of society based on the use of advanced achievements of science, technology, innovation [20].

The processes of modernization of the domestic economy and society as a whole, focused on the development of market relations in the digital economy, significantly affect the development of educational institutions. Accordingly, the processes of commercialization in the educational sphere are spreading, which gradually requires the existence of new rules of interaction, status-role relationships, value and normative formations [21]. However, modern transformations are accompanied by negative trends in the development of the education system and the use of accumulated intellectual assets. This is due to the 
devaluation of knowledge and diplomas, social insecurity of intellectual labor and a decrease in public requests for specialists, weakening and loss of ties between educational and industrial structures, etc. [22].

According to the national strategy for the development of education in Ukraine for 2012-2021 [23], education belongs to the most important directions of the state policy of Ukraine, because it is a strategic resource for socio-economic, cultural and spiritual development of the society, improving the well-being of people, ensuring national interests, strengthening international authority and forming a positive image of our state, creating conditions for selfrealization of each individual. However, it is very slow to implement certain priorities in real life. As a result, the unsatisfactory state of domestic education and its inconsistency not only with the European and global, but also with the domestic labor market.

A significant innovative component of the domestic educational space is technical training, which can be roughly represented by four groups: vocational, special technical, higher technical and postgraduate education. Today, it is not customary to classify technical specialties of higher education in Ukraine as elite, since the humanities are in the lead. However, if we assess the real picture in the labor market of Ukraine and its regions, about $40-50 \%$ of the unemployed are young people, most of whom have mastered humanitarian specialties. In addition, the basis of the economic system - its industry - suffers significant losses, so we can confidently say that the overwhelming number of humanitarians in comparison with engineering workers does not benefit the state as a whole and separate region.

In the Ukrainian society, there is no demand for high-quality education in the field of exact and engineering sciences, as evidenced by entrance campaigns in recent years. However, it is known that in the modern world, the competitiveness of the state is determined by the number of physicists, mathematicians, engineers, designers and technologists.

In Ukraine, the largest share of people with full higher education is concentrated in the financial sector (59.7\%), public administration (59.5\%) and education (47.3\%) [24]. Accordingly, these areas are characterized by high social status and economic prestige, especially for young people with higher education. As a result, the training of specialists in these areas exceeds the demand for them from the national economy, and in technical specialties, on the contrary, it does not meet the demand.

Taking into account the current situation, the Ukrainian government in recent years has increased state order for technical specialties (electronics, energy, mechanical engineering, radio engineering, radioelectronic devices and communications, metallurgy and materials science, chemical technologies and engineering, specialties related to aviation, transport infrastructure) and reduces management, economics and law. However, even these measures do not make a proper shift.
Negative for Ukraine is not just the process of oversaturation of the labor market itself, but also the wasted part of the state budget (training by state order), which is used to train workers and specialists who are not competitive in the labor market. However, until now, the country has not created an effective monitoring system that would contribute to forecasting and marketing of educational services. The system of vocational education is negatively affected by insufficient involvement of employers and other social partners in the development and approval of educational standards, curricula and programs, and the lack of incentive lending to educational institutions for obtaining equipment and other equipment. The main reasons for problematic situation with the graduates' employment are the following: slow pace of structural changes in the economy, which leads to significant imbalances in the structure of demand in the labor market; increased competition in the labor market of professions and specialties for which training is conducted in educational institutions; non-compliance of the received specialty with the needs of the labor market; lack of practical experience or work experience in the specialty.

An important direction for the development of higher education and improving its quality, as well as the formation of an innovative society in Ukraine, is the integration of science, higher education and business as a process of accumulating resources for the development of the knowledge economy [25]. The formation and effective use of the intellectual basis of human capital takes place in these processes. Integration is able to solve modern socio-economic problems of the domestic economy while uniting around the solution of common urgent tasks, since it is accompanied by the establishment, complication and strengthening of important ties. It allows you to get a number of positive effects (stimulating innovation activity, producing and commercializing innovations, optimizing the use of resources and achieving the highest level of well-being), although it reduces the level of intersectoral competition.

It is proved that integration is mutually beneficial for each of the interacting parties, since it is determined by the needs of society: for scientific organizations (development of the material and technical base and acceleration of commercialization of scientific developments; exchange of innovative developments; expansion of access to information resources); for higher education institutions (attracting teachers, students to research work on the most pressing development problems; improving the level of education by providing access to the latest equipment; strengthening the human potential of higher education institutions and increasing the level of their material support; development of the material and technical base of scientific research; optimization of the educational process; attraction of additional financial resources; rapid implementation of research results in the educational process; further employment of graduates); for production (training on the basis of higher education institutions' qualified personnel who 
are able to be involved in the production process with a minimum adaptation time; direct access to developments necessary to create competitive products, and the ability to adjust them in accordance with needs); for the state (the ability to more efficiently allocate limited resources and activate the economic activity of the population and subjects of the national economy).

Thus, close cooperation between higher education and business is a realistic way of innovative development of the country and an effective means of ensuring competitive production with highly qualified personnel. The formation and development of integration links of science, education and production into a common system can organically combine and ensure more effective functioning of each of these spheres of human activity and will contribute to the development of intellectual assets of human potential.

\section{Conclusions}

To conclude, the presented comparative rating of some world countries proves significant reserves in Ukraine for improvement, remaiming still at lower positions of using intellectual assets of human potential than required by modern world changes.

The indicators of innovation activity in Ukraine point out the lack of a stable development strategy of the country, which causes instability and situativeness of the development of innovative factors of economic growth. In general, the indicators of innovative and technological development of the economy's real sector have remained almost stable in recent years. This highlights the existing pattern regarding the importance of the stabilizing role of innovation factors in economic development.

It has been determined that the cultural and mental characteristics of Ukrainians have a significant impact on the development of intellectual assets of human potential, innovation activity and the effectiveness of innovation activities. In particular, the negative impact of the historical heritage of Ukrainians remains noticeable, when private property was officially absent and a negative attitude to it in the society and business activities was formed. The real disproportionate distribution of benefits, which remains today, has led to a significant loss of trust in the modern Ukrainian society and hinders the development of cooperation, collaboration and integration of various institutions: within the public, education and science, business and government. And today, despite the high level of education coverage, scientific research (being fundamental ones, the findings are sometimes difficult to perceive by the society, do not take into account market demands and global trends, or lack the possibility of practical usage), the level of implementation of intellectual property objects in practice and commercialization of innovations remain low.

In the context of radical technological, economic, and social changes that are taking place in the society, a traditional role of universities as research centers that create new knowledge and training centers for highly professional personnel should be supplemented by an important function - innovative one, which allows to fully integrate the higher education system into society, "open" it to production and the labor market. In other words, there will be more favorable conditions for the formation and effective use of intellectual assets of human potential.

Modern high education institutions that have the resources to fully implement innovation process should become active participants of innovation activity. The latter should be aimed at activating the innovative thinking of students, postgraduates, scientists, and teachers. Higher education institutions should become centers for the emergence and spread of technology transfer processes. That will provide them with the role of one of the key elements in the innovation infrastructure, which acts as a link between science and business.

\section{References}

1. K. Schwab, The Fourth Industrial Revolution (World Economic Forum, Geneva, 2016). ISBN 978-1-944835-01-9

2. V. Vanzha, A. Kukharuk, Staging the process of enhancing of competitiveness of machine-building enterprises in the conditions of Industry 4.0. Cur. Probl. of econ. and manag. 14 (2020)

3. F. Orellana, R. Torres, From Legacy-Based Factories to Smart Factories Level 2 According to the Industry 4.0. Intern. J. of Comp. Integr. Manuf. 32 (4-5), 441-451 (2019). doi: 10.1080/0951192x.2019.1609702

4. T. J. B. Blayone, R. van Oostveen, Prepared for work in Industry 4.0? Modelling the target activity system and five dimensions of worker readiness. Intern. J. of Comp. Integr. Manuf. 32 (4-5), 441451 (2019). doi: 10.1080/0951192X.2020.1836677

5. V. Sima, I. G. Gheorghe, J. Subi'c, D. Nancu, Influences of the Industry 4.0 Revolution on the Human Capital Development and Consumer Behavior: A Systematic Review. SUSTDE. 12 (2020). doi: 10.3390/su12104035

6. A. Łupicka, K. Grzybowska, Key Managerial Competencies for Industry 4.0 - Practitioners', Researchers' and Students' Opinions. Logistic and Transport. 3(39), 39-46 (2018). doi: 10.26411/831734-2015-3-39-4-18

7. J. C. Hayton, G. George, S. A. Zahra, National Culture and Entrepreneurship : A Review of Behavioral Research. ETP. 26(4), 33-52 (2002). doi: $10.1177 / 104225870202600403$

8. S. Dutta, B. Lanvin. The network readiness index 2020. Accelerating Digital Transformation in a post-COVID Global Economy. Portulans Institute. (2020). ISBN 978-1-63649-055-7 
9. S. Dutta, B. Lanvin. The Network Readiness Index 2019: Towards a Future-Ready Society. Portulans Institute. (2019). ISBN: 978-0-578-62273-6

10. S. Baller, S. Dutta, B. Lanvin. The Global Information Technology Report 2016 Innovating in the Digital Economy. World Economic Forum, Geneva (2016). ISBN: 978-1-944835-03-3

11. A. V. Karpenko, Rozvytok intelektual'nykh aktyviv lyuds'koho potentsialu: teoriya ta praktyka (The Development of Intellectual Assets of Human Potential: theory and practice). (FOP V. V. Mokshanov, Zaporizhzhya, 2018); ISBN 978-6177520-52-7

12. Measuring the information society : report. Geneva : International Telecommunication Union, https://www.itu.int/en/ITU-

D/Statistics/Pages/default.aspx

13. The Global Innovation Index, https://www.globalinnovationindex.org/Home

14. Official site of (2020) the State Statistics Service of Ukraine. http://www.ukrstat.gov.ua. Accessed 20 Sept 2020

15. R. L. Florida, The rise of the creative class: and how it's transforming work, leisure, community, and everyday life (Basic Books, New York, 2002). ISBN 978-0-465024-76-6

16. E. Junarsin, Creativity and Competitiveness. Glob. 8, 1-13 (2009)

17. S. L. Mueller, A. S. Thomas, Culture and entrepreneurial potential: a nine country study of locus of control and innovativeness. J. of Bus. Ven. 16, 51-75 (2001). doi: 10.1016/S08839026(99)00039-7

18. A. Karpenko, K. Basenko, Highly Effective Corporate Culture as an Instrument of Talents' Attracting and Retaining. Balt. J. of Econ. Stud. 3(4), 101-106 (2017). doi: 10.30525/22560742/2017-3-4-101-106

19. O. Bilenko, Mentality as an institutional factor in the development of human capital. Instit. Vect. of Econ. Devel. 5(2), 26-34 (2020)

20. V. I. Kutsenko, V. P. Udovychenko, Ya. V. Ostafiichuk, Suspilnyi vektor staloho rozvytku: teoriia ta praktyka (Social vector of sustainable development). (Lozovyi V. M., Chernihiv, 2013)

21. M. V. Klov, Commercialization of higher education: characteristics and development trends. Grani. 5, 85-91 (2014)

22. A. A. Pakulina, Innovative development of the higher education system, which promotes the commercialization and transfer of technology. Econ. Scope. 70, 266-274 (2013)

23. Natsionalna stratehiia rozvytku osvity v Ukraini na 2012-2021 roky (National strategy for the development of education in Ukraine for 20122021), http:/guonkh.gov.ua/content/documents/16/1517/ Attaches/4455.pdf

24. D. P. Melnychuk, Educational structure of the population: ways of optimization in the context of preservation and development of human capital of Ukraine. Ukraine: asp. of work. 8, 21-26 (2009)

25. V. S. Ponomarenko, O. V. Raievnieva (eds.), Intehrovana systema "Vyshcha shkola - biznes struktura» : metodolohiia ta kontseptualni zasady pobudovy (Integrated system "Higher school business structure": methodology and conceptual principles of construction). (INZHEK, Kharkiv, 2011) 